OPEN ACCESS

Edited by:

Qingfeng Zhang,

Tongji University, China

Reviewed by:

Xiaolei Liu,

Jilin University, China

Lilián Yépez-Mulia,

Unidad de Investigación en

Enfermedades Infecciosas y

Parasitarias, Instituto Mexicano del

Seguro Social (IMSS), Mexico

${ }^{*}$ Correspondence:

Zhong Quan Wang

wangzq@zzu.edu.cn

Jing Cui

cuij@zzu.edu.cn

Specialty section:

This article was submitted to Molecular and Cellular Pathology, a section of the journal Frontiers in Cell and Developmental Biology

Received: 23 June 2021

Accepted: 24 August 2021 Published: 20 September 2021

Citation:

Zhuo TX, Wang Z, Song YY, Yan SW, Liu RD, Zhang X, Wang ZQ and Cui J (2021) Characterization of a Novel Glutamine Synthetase From Trichinella spiralis and Its Participation in Larval Acid Resistance, Molting, and Development. Front. Cell Dev. Biol. 9:729402. doi: 10.3389/fcell.2021.729402

\section{Characterization of a Novel Glutamine Synthetase From Trichinella spiralis and Its Participation in Larval Acid Resistance, Molting, and Development}

\author{
Tong Xu Zhuo, Zhen Wang, Yan Yan Song, Shu Wei Yan, Ruo Dan Liu, Xi Zhang, \\ Zhong Quan Wang* and Jing Cui* \\ Department of Parasitology, Medical College, Zhengzhou University, Zhengzhou, China
}

Trichinella spiralis is a major foodborne parasite worldwide. After the encapsulated muscle larvae $(\mathrm{ML})$ in meat are ingested, the $\mathrm{ML}$ are liberated in the stomach of the host and activated into intestinal infectious larvae (IIL), which develop into adult worm after molting four times. A novel glutamine synthetase (TsGS) was identified from T. spiralis IIL at $10 \mathrm{~h}$ post-infection, but its biological role in T. spiralis life cycle is not clear. The aim of this study was to investigate the biological characteristics of TsGS and its functions in larval acid resistance, molting, and development. TsGS has a glutamine synthetase (GS) catalytic domain. Complete TsGS sequence was cloned and expressed in Escherichia coli BL21. rTsGS has good immunogenicity. qPCR and Western blotting showed that TsGS was highly expressed at IIL stage, and immunofluorescence revealed that TsGS was principally localized at the cuticle and intrauterine embryos of this nematode. rTsGS has enzymatic activity of natural GS to hydrolyze the substrate (Glu, ATP, and $\mathrm{NH}_{4}{ }^{+}$). Silencing of TSGS gene significantly reduced the IIL survival at $\mathrm{pH} 2.5$, decreased the IIL burden, and impeded larval molting and development. The results demonstrated that TsGS participates in T. spiralis larval acid resistance, molting and development, and it might be a candidate vaccine target against Trichinella molting and development.

Keywords: Trichinella spiralis, glutamine synthetase, molting, acid resistance, RNAi

\section{INTRODUCTION}

Trichinella spiralis is a serious foodborne zoonotic parasitic nematode and the principal causative agent of human trichinellosis. T. spiralis infection in humans is mainly resulted from eating poorly cooked or raw infected pork in most countries (Cui et al., 2013a; Jiang et al., 2016; Rostami et al., 2017). Various T. spiralis developmental stage worms are parasitized within the same host; adult worms (AW) and muscle larvae (ML) dwell in the duodenum and upper jejunum and skeletal muscles, respectively. After ingestion, the ML encapsulated in muscle tissues are released from their collagen capsules under the digestion of gastric pepsin and activated into intestinal infectious 
larvae (IIL) after being contacted with enteral contents or bile (Ren et al., 2011; Liu et al., 2013). The IIL intrude intestinal epithelium cells (IECs) and develop to adulthood in gut epithelial intramulticellular niche after going four molts. Molting is a prerequisite step for larval growth and development of the parasitic nematode. If their molting could not be completed, the larvae cannot continue to develop and grow (Gagliardo et al., 2002; Ren et al., 2013). Therefore, larval molting-related proteins are likely the potential targets to develop new drugs or vaccines against nematode infection.

Glutamine synthetase (GS) is widely distributed in microorganisms, animals, and higher plants. It participates in many biological processes and is regarded as an ideal evolutionary molecular clock (Kumada et al., 1993). GS produces glutamine using glutamate and ammonia in the presence of ATP and $\mathrm{Mg}^{2+}$. Glutamine is the carbon and nitrogen donor for the production of biomolecules and participates in the dynamic balance of redox. GS is the key enzyme of nitrogen metabolism in organisms. The physiological process of nitrogen assimilation is very important in the process of organism growth and development. GS is a major enzyme involved in ammonia assimilation. In the presence of $\mathrm{Mg}^{2+}$ and energy supplied by ATP, GS catalyzes the assimilation of $\mathrm{NH}_{4}{ }^{+}$to glutamine. Glutamine produces glutamate under the catalysis of GS. In nitrogen metabolism, glutamine serves not only as a temporary storage and transport form of toxic glutamic acid and ammonia but also as a nitrogen donor of amino acids, nucleic acids, and hexosamine. Although there are many metabolic pathways of glutamine, GS is the only enzyme in the de novo synthesis of glutamine. GS is also an indispensable detoxifying enzyme in stress and immune response (Lai et al., 2011; Wang et al., 2014). In Trypanosoma cruzi, GS is necessary to resist ammonium accumulation toxicity and immune escape during host cell infection (Crispim et al., 2018). However, there are no reports on the biological properties and functions of the GS in the life cycle of $T$. spiralis in the literatures.

Escherichia coli is a kind of bacteria which is closely related to the daily life of people. As a foodborne pathogen, E. coli must pass through the extremely sour stomach of mammals to cause a disease. E. coli is resistant to very low $\mathrm{pH}$ levels and can survive at $\mathrm{pH} 2.5$ for more than $2 \mathrm{~h}$, mainly due to complex acid-resistant systems (Jin et al., 2009). At present, there are four main anti-acid systems known: glucose-inhibited acid-fast system, glutamate-dependent acid-fast system, argininedependent acid-fast system, and glutamine-dependent acid-fast system (AR4). When bacteria are in acidic conditions, they will induce the synergistic action of multiple acid-resistant systems (ARs) in hosts so as to survive in acidic conditions. Organisms survive within the appropriate $\mathrm{pH}$ range. In physiological and biological buffering systems, ammonia and carbon dioxide mainly regulate the $\mathrm{pH}$ (Krulwich et al., 2011). The pathogenicity of foodborne pathogens determines the inevitability of their acid tolerance. Stimulation in an acidic environment leads to the expression of acid-resistant genes in pathogens (Djoko et al., 2017). T. spiralis is a foodborne parasite, and the ML might have acid-resistant genes to protect the larvae from gastric acid damage (Zhang et al., 2010). AR4 is one of the most important acid-resistant systems in E. coli. Recent studies showed that glutaminase is an important gene in glutaminedependent acid resistance of T. spiralis ML (Gao et al., 2021). However, there are no reports on the GS role in T. spiralis ML acid resistance.

In our previous study, a novel T. spiralis GS (TsGS; GenBank: XM_003374954.1) was identified in somatic crude proteins of 10$\mathrm{h}$ IIL in the process of first larval ecdysis (Ren et al., 2019). The aim of this study was to investigate the biological properties and roles of TsGS in larval acid resistance, molting, and development of T. spiralis.

\section{MATERIALS AND METHODS}

\section{Parasites, Animals, and Antigens}

The parasite T. spiralis (ISS534) was acquired from an infected domestic pig in central China (Wang et al., 2012) and maintained in our laboratory by serial passage in BALB/c mice. Female $\mathrm{BALB} / \mathrm{c}$ mice of 4-6 weeks old were purchased from Henan Provincial Experimental Animal Center (Zhengzhou, China). The ML was recovered by artificial digestion of infected mouse carcasses at 42 days post-infection (dpi) with $0.33 \%$ pepsin (1:31,000; Sigma-Aldrich, United States) and 1\% HCl (Jiang et al., 2012). The IIL and AW were collected from infected murine small intestine (Sun et al., 2015a,b). The adult females at 6 dpi were cultured in RPMI-1640 with 10\% fetal bovine serum (Gibco, Auckland, New Zealand) at $37^{\circ} \mathrm{C}$ in $5 \% \mathrm{CO}_{2}$ for $24 \mathrm{~h}$, and the newborn larvae (NBL) were harvested as previously described (Li et al., 2015; Wu et al., 2016). The somatic crude proteins of diverse T. spiralis phases (ML, IIL, AW, and NBL) and IIL ES proteins were prepared as reported before (Yang et al., 2015).

\section{Bioinformatics Analysis of TsGS}

The complete cDNA sequence of the TsGS gene was obtained from GenBank (GenBank: XM_003374954.1), and its physicochemical characteristics and structures were analyzed and predicted by NCBI online website. Multi-sequence alignment was carried out between TsGS and GS from Trichinella spp. by using Clustal X (Li et al., 2015). The GenBank accession numbers of GS from Trichinella spp. and other organisms were as follows: Trichinella nativa (KRZ52922.1), Trichinella britovi (KRY49640.1), Trichinella T6 (KRX74386.1), Trichinella T8 (KRZ85490.1), Trichinella T9 (KRX59460.1), Trichinella murrelli (KRX49151.1), T. patagoniensis (KRY23667.1), Trichinella zimbabwensis (KRZ13164.1), Trichinella papuae (KRZ68830.1), Trichinella pseudospiralis (KRZ22405.1), Mus musculus (NP_032157.2), and Homo sapiens (NP_001028228.1). The phylogenetic tree was constructed using MEGA 7.0 based on the neighbor-joining method as reported previously (Qi et al., 2018b; Hu et al., 2020).

\section{Cloning, Expression, and Identification of rTsGS}

Total RNA was extracted from the 6-h IIL using Trizol (Invitrogen, United States), and EcoRI and SalI (italicized) 
were used as restriction sites to design TsGS-specific primers (5'-CCGG AATTCATGGCATTCACGTTGACATTGAGCT$3^{\prime}$ and 5'-CCGACGTCGACTTACTCTCTT AAACAAA TGGTACGCACC $\left.-3^{\prime}\right)$. The complete TsGS cDNA sequence was amplified by PCR. The PCR product was cloned into the pET-28a carrying a His-tag at N-terminus (Novagen, United States), and recombinant pET-28a/TsGS was transformed into E. coli BL21 (Novagen). The expression of rTsGS was induced with $0.5 \mathrm{mM}$ isopropyl $\beta$-D-1-thiogalactopyranoside at $30^{\circ} \mathrm{C}$ for $8 \mathrm{~h}$ (Xu et al., 2018). A Ni-NTA-Sefinose resin containing His tag (Sangon Biotech, Shanghai, China) was used to purify rTsGS (Sun et al., 2018). The expression of rTsGS protein was analyzed by SDS-PAGE as described above (Xu et al., 2020).

\section{Preparation and Measurement of Anti-rTsGS Antibodies}

Twenty mice were immunized subcutaneously with $20 \mu \mathrm{g}$ rTsGS mixed with complete Freund's adjuvant. Boost immunization was performed three times with $20 \mu \mathrm{g}$ rTsGS mixed with incomplete Freund's adjuvant at a 2-week interval (Zhang et al., 2020). At 2 weeks after the last immunization, the tail blood of immunized mice was collected to isolate anti-rTsGS immune sera (Cui et al., 2013b).

The anti-rTsGS IgG level of all immunized mice was assessed by ELISA (Cui et al., 2015b). Briefly, micro-plates were coated with $2 \mu \mathrm{g} / \mathrm{ml}$ rTsGS at $37^{\circ} \mathrm{C}$ for $2 \mathrm{~h}$. After washing with phosphate-buffered saline (PBS; $\mathrm{pH} 7.4$ ) containing $0.05 \%$ Tween-20, the plate was blocked with $5 \%$ skimmed milk at $37^{\circ} \mathrm{C}$ for $2 \mathrm{~h}$. Following a wash, the diluted antirTsGS sera were added and incubated at $37^{\circ} \mathrm{C}$ for $2 \mathrm{~h}$ and then by incubation of HRP-conjugated anti-mouse IgG (1:10,000; Southern Biotech, United States) at $37^{\circ} \mathrm{C}$ for $1 \mathrm{~h}$. Coloration was performed using OPD (Sigma-Aldrich) plus $\mathrm{H}_{2} \mathrm{O}_{2}$; the reaction was finished by the addition of $2 \mathrm{M}$ $\mathrm{H}_{2} \mathrm{SO}_{4}$. The optical density values at $492 \mathrm{~nm}$ were measured by a microplate reader (Tecan Schweiz AG, Switzerland) (Liu L. N. et al., 2015).

\section{Western Blotting Analysis}

Soluble crude proteins from diverse T. spiralis phase worms, 6$\mathrm{h}$ IIL ES proteins, and rTsGS were separated by $12 \%$ SDS-PAGE (Wang et al., 2013; Ren et al., 2018). The proteins were transferred onto a nitrocellulose membrane (Millipore, United States). The membrane was blocked with 5\% skimmed milk diluted in Trisbuffered saline ( $\mathrm{pH}$ 7.4) containing $0.05 \%$ Tween-20 (TBST)
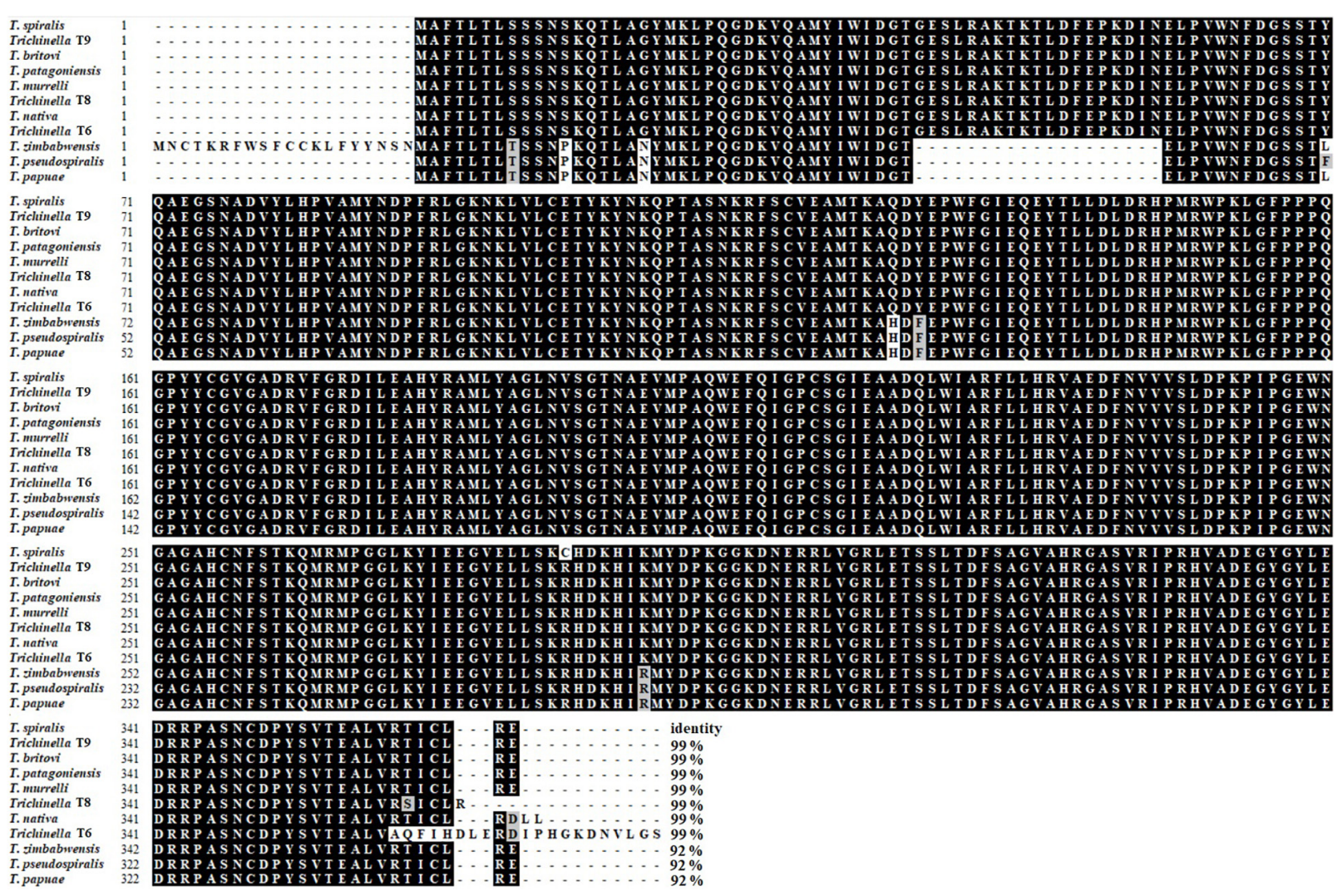

FIGURE 1 | Sequence alignment of TsGS with other species or genotypes of the genus Trichinella. Multiple sequence alignment was carried out by using BioEdit, the black shadow represents the same residue as TsGS, and the gray shadow is a conservative substituent. The number at the end of each sequence represents the percentage of identity with TsGS. 
at $37^{\circ} \mathrm{C}$ for $2 \mathrm{~h}$ and cut into strips. The strips were probed with 1:100 dilutions of various sera (anti-rTsGS serum, infection serum, and normal serum) at $37^{\circ} \mathrm{C}$ for $2 \mathrm{~h}$. After washing with TBST, the strips were incubated with HRP-conjugated antimouse IgG (1:10,000; Southern Biotech, United States) at $37^{\circ} \mathrm{C}$ for $1 \mathrm{~h}$. After washing again, the strips were developed with 3,3'diaminobenzidine tetrahydrochloride (Sigma-Aldrich) or using an enhanced chemiluminescent kit (CWBIO, Beijing, China) and terminated by washing the membrane with deionized water (Long et al., 2014; Liu et al., 2018).

\section{qPCR}

Total RNAs from diverse T. spiralis phases (ML, 6- and 10-h IIL, 3-day AW, and NBL) were extracted with Trizol (Invitrogen). The TsGS transcription levels at various stage worms were ascertained by qPCR as described before (Long et al., 2015; Hu et al., 2021). The TsGS-specific primers for qPCR amplification were as follows: 5'-AGTGACTGGAATGTTTGGAGA$3^{\prime}$ and $5^{\prime}$-AATCAGTTCCTGTGATGCC- $3^{\prime}$. The relative TsGS transcription level was normalized by subtracting the transcription of a $T$. spiralis housekeeping gene tubulin (GenBank: XM_003369432.1; 5'-TGCATTGGTACACTGGAGAAG-3' and 5' GCTTCCTGGTACTGCTG ATATT-3') (Yang et al., 2010) and then calculated according to comparative Ct $(2-\Delta \Delta \mathrm{Ct})$ method (Xu et al., 2021). Each experiment had three repeats.

\section{Indirect Immunofluorescence Assay}

Whole worms of different T. spiralis stages (ML, IIL, AW, and NBL) were fixed with $4 \%$ formaldehyde for $30 \mathrm{~min}$ and refixed with cold acetone for $20 \mathrm{~min}$. The fixed worms were embedded in paraffin and cut into a 2 - $\mu$ m-thick cross-section

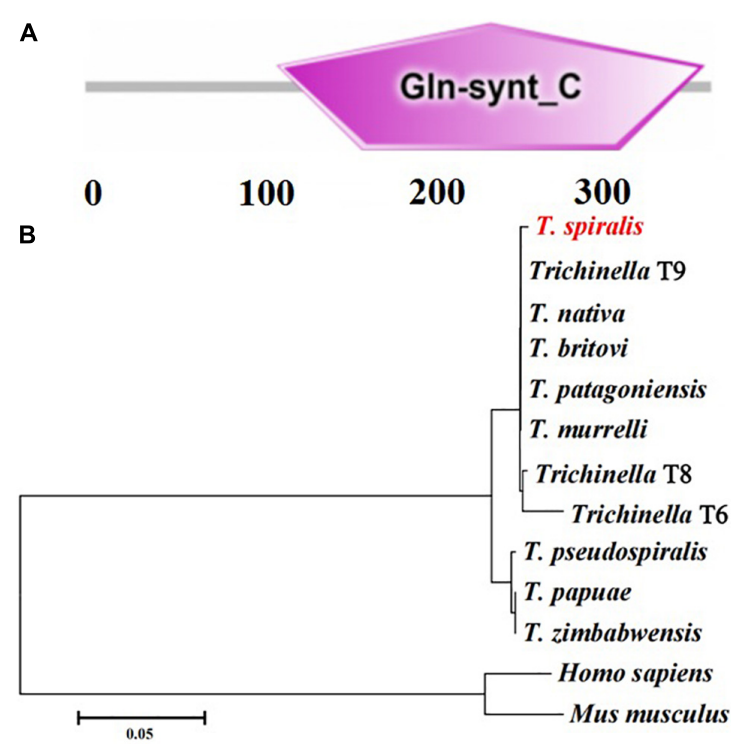

FIGURE 2 | The predicted TsGS catalytic domain (Gln-synt_C) (A) and phylogenetic trees of glutamine synthetase of 13 organisms with neighbor-joining method (B). with a microtome. The expression and tissue location of native TsGS in various worm stages were investigated by indirect immunofluorescent assay (IIFA) (Liu et al., 2017; Cui et al., 2019). Whole parasites and their cross-sections were blocked with 5\% normal goat serum for $2 \mathrm{~h}$ and then probed at $37^{\circ} \mathrm{C}$ for $2 \mathrm{~h}$ with 1:10 diluted diverse sera (anti-rTsGS serum, infection serum, and normal serum). After washes with PBS, the worms were stained using goat anti-mouse IgG-FITC conjugate (1:100; Santa Cruz, United States). Following washes again, whole worms and cross-sections were examined under a fluorescence microscope (Olympus, Tokyo, Japan) (Lei et al., 2020; Yue et al., 2020).

\section{Measurement of rTsGS Enzyme Activity}

Since rTsGS was expressed in the form of inclusion body, rTsGS was first re-naturated by dilution refolding method (Li et al., 2009; Liu L. N. et al., 2015). To assess the enzyme activity of rTsGS, the diluted rTsGS $(0.05-1.00 \mu \mathrm{g} / \mu \mathrm{l})$ was incubated at $35^{\circ} \mathrm{C}$ for $15 \mathrm{~min}$ in various $\mathrm{pH}$ buffers $(\mathrm{pH} 3.0-$ 10.5). Subsequently, the GS substrates (Glu, ATP, and $\mathrm{NH}_{4}{ }^{+}$) were added to the reaction mixture and incubated at different temperatures $\left(20-70^{\circ} \mathrm{C}\right)$ for $30 \mathrm{~min}$, and the absorbance at $660 \mathrm{~nm}$ was measured with a spectrophotometer. In order to evaluate the effect of different metal ions on the rTsGS enzyme activity, the metal ions $\left(\mathrm{Mg}^{2+}, \mathrm{Zn}^{2+}, \mathrm{Mn}^{2+}, \mathrm{Ca}^{2+}\right.$, $\mathrm{Fe}^{2+}, \mathrm{Co}^{2+}, \mathrm{Cu}^{2+}$, and $\mathrm{Ni}^{2+}$ ) were added to the reaction system. Different enzyme inhibitors ( $1 \mathrm{mM}$ AEBSF, $5 \mu \mathrm{M}$ E$64,10 \mu \mathrm{M}$ EDTA, and $10 \%$ glufosinate) were used to ascertain the effects of the inhibitors on rTsGS enzyme activity. According to the change of absorbance at $\mathrm{OD}_{660}$ of $\mathrm{KH}_{2} \mathrm{PO}_{4}$ standard solution with a concentration of $0.1-1.0 \mathrm{mM}$, the standard curve of phosphorus was calculated. The concentration range of monosodium glutamate (Glu), ATP, and ammonium $\left(\mathrm{NH}_{4}{ }^{+}\right.$) was set to $0.5-5 \mathrm{mM}$. The $\mathrm{Km}$ value was obtained from MichaelisMenten curve and Lineweaver-Burk curve (Cui et al., 2015a; Guo et al., 2020).

The enzymatic activity of natural TsGS in somatic proteins of various worm stages was assessed by using the Micro GS Assay Kit (Solarbio, Beijing, China) (Wang et al., 2018).

\section{RNA Interference}

TsGS-specific siRNA-356 (5'-UCAAUGUCAACGUGAAUGC CA-3' and 5'-GCAUUCACGU UGACAUUGAGC-3') was designed according to the full-length TsGS cDNA sequence and prepared by Sangon Biotech (Shanghai, China). Additionally, a control siRNA with a scrambled sequence (5'-AUCGGCUACCAAGUCAUACTT- $3^{\prime}$ and $5^{\prime}$ GUAUGACUUGGUAGCCGAUTT-3') was also synthesized. The control siRNA was fluorescently labeled with 5carboxyfluorescein (FAM; Sangon Biotech) and used to detect the transfection efficiency. The siRNA-356 is transfected into the ML by electroporation; all the silenced and non-silenced ML were cultured for 1-3 days in RPMI-1640 at $\mathrm{pH} 7.4,37^{\circ} \mathrm{C}$, and $5 \% \mathrm{CO}_{2}$ (Wang et al., 2015). The TsGS transcription and expression levels in the ML after RNAi were determined by qPCR and Western blotting as described before (Yang et al., 2019; Yi et al., 2020). A T. spiralis housekeeping gene tubulin was used as an internal control. The protein expression level was measured 
based on densitometry, and the data showed the relative protein expression assessed in three repeated experiments (Xu et al., 2021). The TsGS activity in the crude extract of the siRNA-treated ML was determined using a Micro GS Assay Kit (Solarbio) (Wang et al., 2018), and the results were compared with the untreated ML.

\section{The Muscle Larvae Acid Resistance Assay}

To investigate the effect of acidic conditions on the survival of

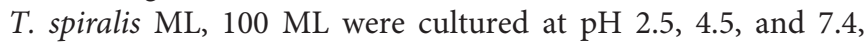
$37^{\circ} \mathrm{C}$, and $5 \% \mathrm{CO}_{2}$ for $2.5,12$, and $18 \mathrm{~h}$. The survival of the ML cultured in $\mathrm{PBS}$ with various $\mathrm{pH}$ values was examined under a microscope on the basis of larval viability. Inactive, straight, or C-shaped larvae were assessed as dead larvae. The mobile and wriggly larvae were counted as live ones (Yang et al., 2020; Gao et al., 2021). Somatic crude extracts from the ML cultured at various $\mathrm{pH}$ values for $18 \mathrm{~h}$ were prepared, and TsGS enzymatic activity was assessed as described before (Wang et al., 2018). In order to evaluate the effects of glutamine on larval survival under acidic condition, the ML were cultivated in PBS supplemented with various doses of glutamine under $\mathrm{pH} 2.5$ condition. Besides this, the acid resistance of the ML transfected with siRNA-356 was also ascertained; the siRNA-356-treated ML was cultured under different $\mathrm{pH}$ for various times, and the larval survival was examined under a microscope (Zhang et al., 2016).

\section{Challenge Infection Experiment With siRNA-356-Treated Larvae}

To investigate the larval infectivity, molting, and development, survival, and fecundity in the small intestine of infected mice after RNAi treatment, 80 mice were divided into four groups (20 animals per group). Each mouse was infected orally with $500 \mathrm{ML}$ treated with $3 \mu \mathrm{M}$ siRNA-356, control siRNA, only inhibitor, or PBS alone. Ten infected mice from each group were euthanized at $24 \mathrm{~h}$ post-infection (hpi) and 6 dpi, respectively.
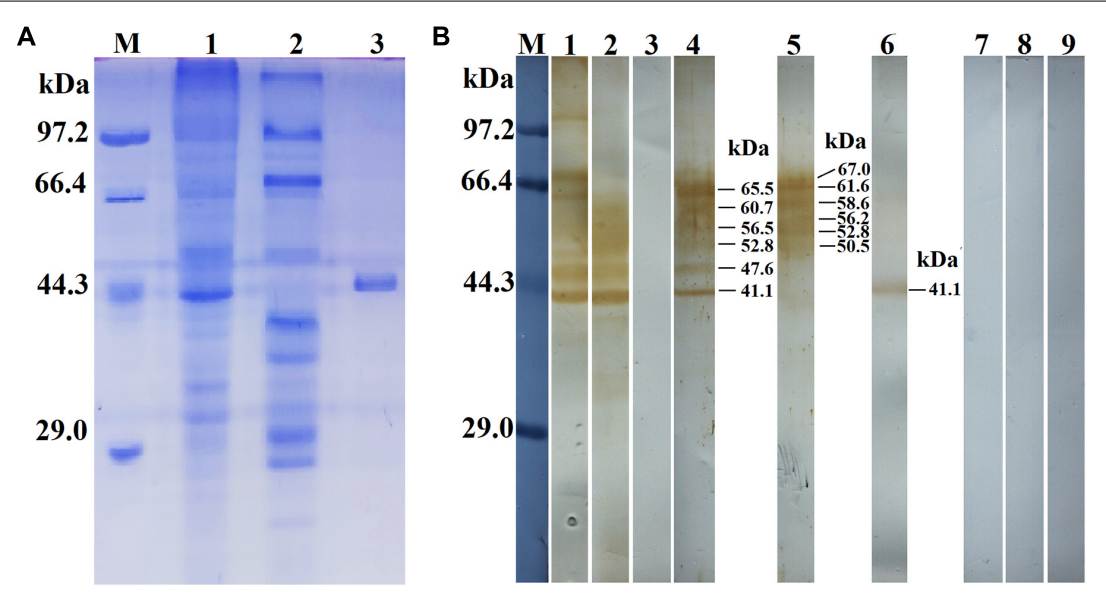

FIGURE 3 | Identification of rTsGS antigenicity. (A) SDS-PAGE analysis of rTsGS. Lane M, protein marker; lane 1, intestinal infectious larvae (IIL) crude proteins; lane 2, IIL ES proteins; lane 3, rTsGS. (B) Western blotting of rTsGS antigenicity. IIL crude proteins (lane 1) and IIL ES proteins (lane 2) were recognized by infection serum, but rTsGS (lane 3) was not recognized by infection serum. Native TsGS in IIL crude proteins (lane 4) and IIL ES proteins (lane 5) and rTsGS (lane 6) were identified by anti-rTsGS serum. IIL crude proteins (lane 7), IIL ES proteins (lane 8), and rTsGS (lane 9) were not recognized by normal mouse serum.
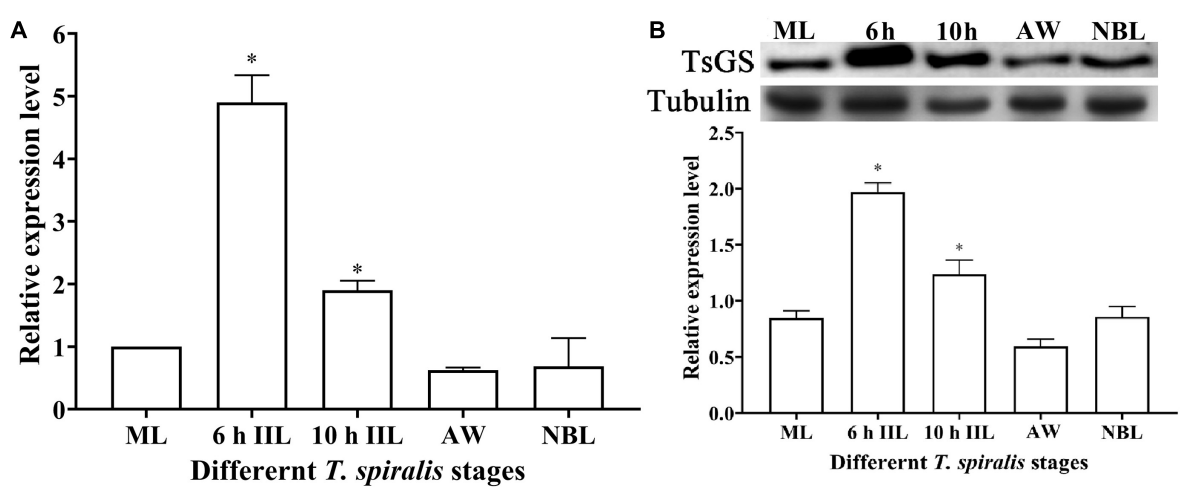

FIGURE 4 | Transcription and expression of TsGS in various Trichinella spiralis stages. (A) qPCR analysis of TsGS transcription in various T. spiralis stages. (B) Western blotting of TsGS expression in somatic proteins of muscle larvae (ML), 6-h intestinal infectious larvae (IIL), 10-h IIL, 3-day adult worms (AW), and newborn larvae (NBL). The TsGS expression level in IIL stages was significantly higher than in other stages. ${ }^{*} P<0.05$ compared with the ML group. 


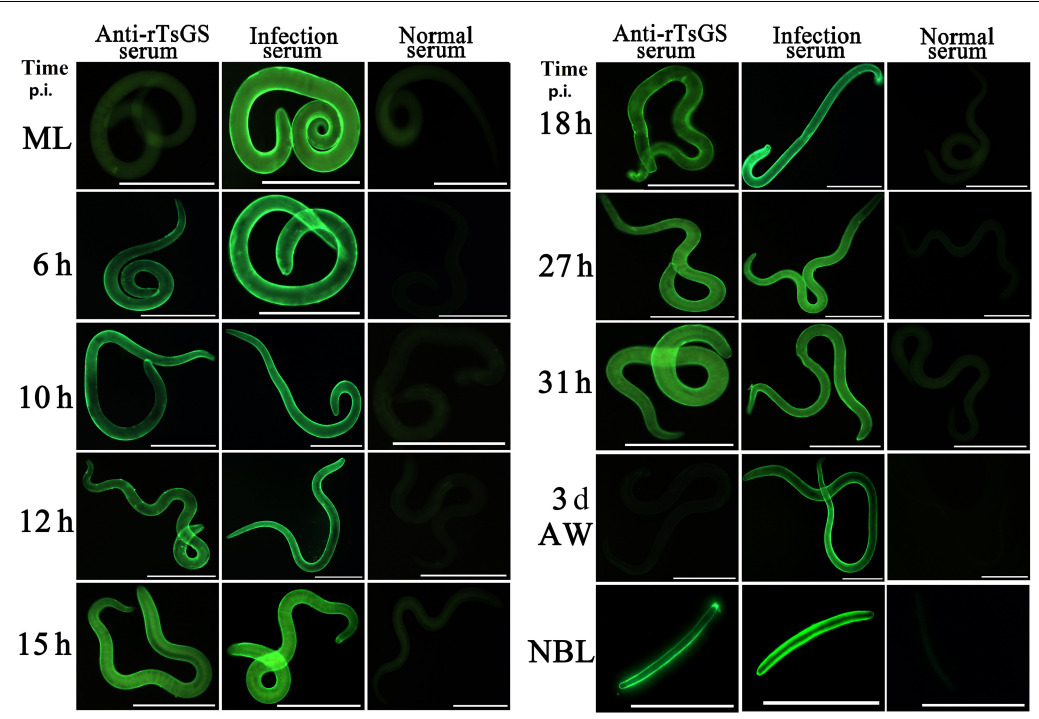

FIGURE 5 | Expression of TsGS on the surface of various Trichinella spiralis stages by IIFA with anti-rTsGS serum. The IIFA was performed with whole intact worms of different $T$. spiralis stages [muscle larvae (ML), 6-31-h intestinal infectious larvae (IIL), adult worms (AW), and newborn larvae (NBL)]. The worms were blocked with $5 \%$ normal goat serum at $37^{\circ} \mathrm{C}$ for $2 \mathrm{~h}$ and then probed at $37^{\circ} \mathrm{C}$ for $2 \mathrm{~h}$ with 1:10 diluted diverse sera (anti-rTsGS serum, infection serum, and normal serum). After washes with phosphate-buffered saline, the worms were stained using 1:100 dilutions of goat anti-mouse IgG-FITC conjugate and examined under fluorescence microscopy. Intense fluorescence staining was observed on the epidermis of IIL, AW, and NBL by using anti-rTsGS serum, but not at ML and AW stages. The worms recognized by infection serum served as a positive control and normal serum as the negative control. Scale bars $=100 \mu \mathrm{m}$.

Intestinal IIL and AW were recovered and numbered, and the intestinal worm burdens of IIL and AW were assessed. Their morphology and size were examined on a microscope (Liu P. et al., 2015; Qi et al., 2018a). Female adults from each group of infected mice were cultivated, and female reproduction capacity (fecundity) was assessed in accordance with NBL production by each female in $72 \mathrm{~h}$ (Sun et al., 2019; Guo et al., 2020).

\section{Statistical Analysis}

All the data were processed by SPSS 21.0 software. The data were presented as mean \pm standard deviation (SD). TsGS expression level, worm burdens and length, and female fecundity among various groups was analyzed with one-way ANOVA. Chi-square test was used to analyze larval survival at different $\mathrm{pH}$ values. $P<0.05$ is regarded as statistically significant.

\section{RESULTS}

\section{Bioinformatics Analysis of TsGS}

The complete TsGS sequence was 1,098 bp encoding 365 amino acids and with a molecular weight (MW) of $41.1 \mathrm{kDa}$ and pI 6.71. The amino acid sequence of TsGS had an identity of $99 \%$ from seven encapsulated Trichinella species (T9, T. britovi, T. patagoniensis, T. murrelli, T8, T. nativa, and T6) and $92 \%$ of three non-encapsulated species (T. zimbabwensis, T. pseudospiralis, and T. papuae) (Figure 1). TsGS had no obvious hydrophobicity and no signal peptide sequence and transmembrane domain. TsGS had a GS catalytic domain (Glnsynt_C) (Figure 2A). The phylogenetic tree of TsGS with GS of other Trichinella species/genotypes is shown in Figure $\mathbf{2 B}$. The phylogenetic tree showed that a monophyletic group of the genus Trichinella was well supported. Within the genus Trichinella, two clear clades were present: one was the clade of eight encapsulated species/gene types (T. spiralis, T9, T. nativa, T. britovi, T. patagoniensis, T. murrelli, T8, and T6), and

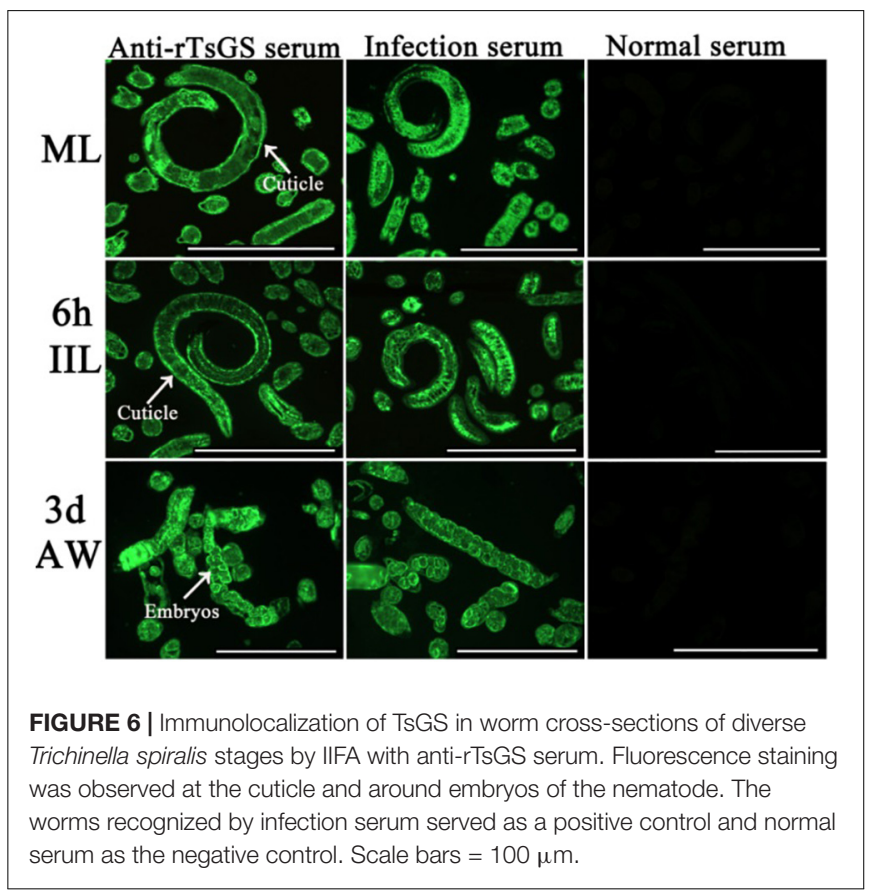


the other was the clade of three non-encapsulated species (T. pseudospiralis, T. papuae, and T. zimbabwensis).

\section{Cloning, Expression, and the Antigenicity of rTsGS}

The results of the SDS-PAGE revealed that the MW of the rTsGS expressed by BL21 bacteria carrying pET-28a/TsGS was $41.1 \mathrm{kDa}$, which was consistent with the predicted TsGS size (Figure 3A). On Western blot analysis, rTsGS was recognized by anti-rTsGS serum, but not by infection serum and normal serum (Figure 3B). Moreover, natural TsGS with $41.1-67 \mathrm{kDa}$ in 6-h IIL soluble and ES proteins was identified by antirTsGS serum, suggesting that TsGS was a worm somatic and excretory/secretory protein.

\section{Transcription and Expression of TsGS in Diverse Worm Phases}

The qPCR results showed that the TsGS transcription level in 6and 10-h IIL stages was statistically higher than in other worm stages (ML, AW, and NBL) $(F=116.073, P<0.05)$ (Figure 4A). On Western blotting with anti-rTsGS serum, the natural TsGS expression level in 6- and 10-h IIL was also significantly higher

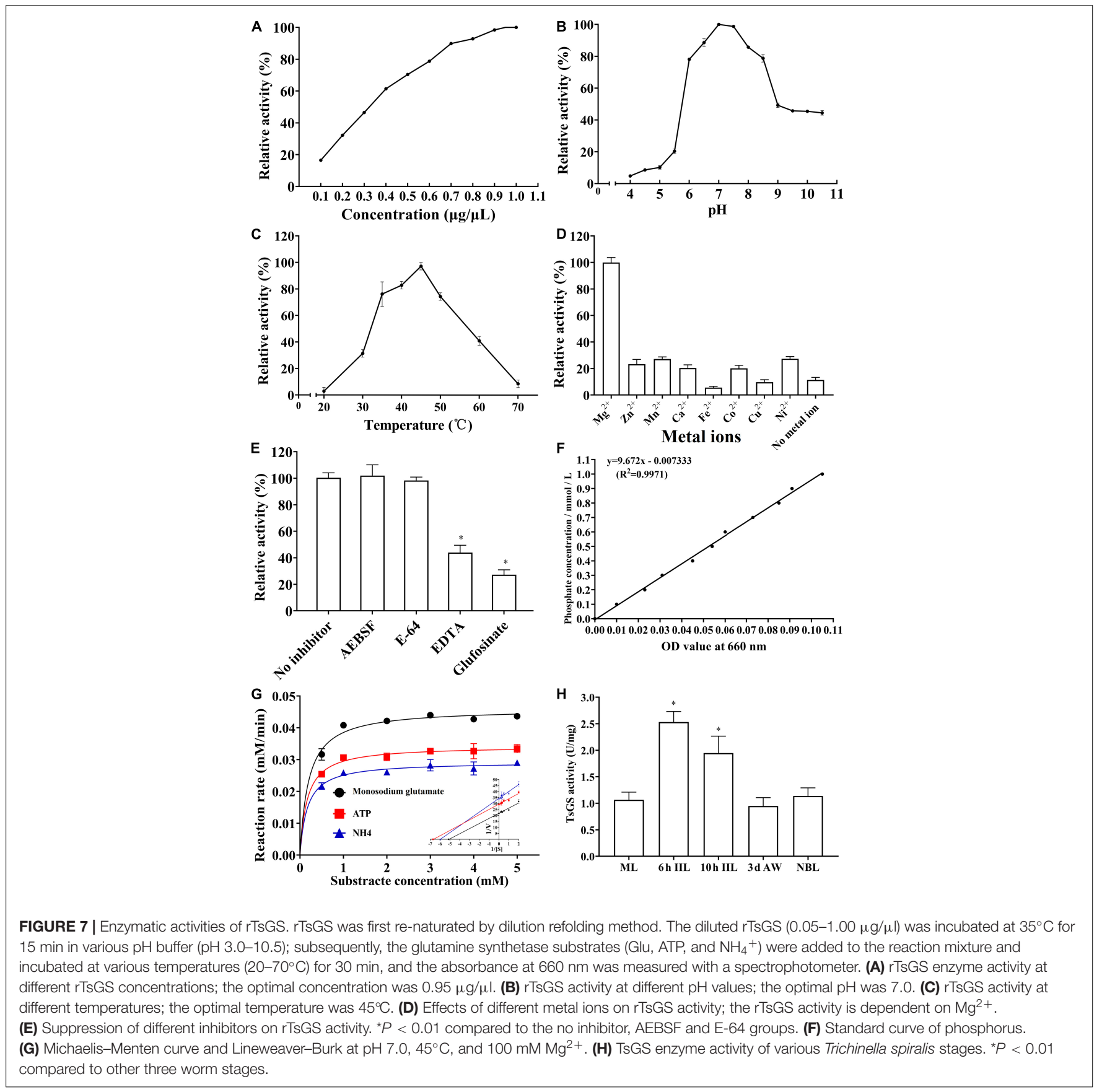


than in the other three worm stages (ML, AW, and NBL) $(F=108.254, P<0.01)$ (Figure 4B), suggesting that TsGS might be a molting-related protease of the IIL stages.

\section{Expression and Worm Tissue Location of Native TsGS in Diverse Trichinella spiralis Stage}

The results of IIFA with intact parasites revealed that intense immunostaining on the epicuticle of 6-of-h IIL, 31-h pre-adults, and NBL was observed by using anti-rTsGS serum (Figure 5), but not on the epicuticle of ML and adult stages. When the worm cross-sections were probed by anti-rTsGS serum, the immunostaining was localized at the cuticle of ML and IIL and around embryos in the female uterus of this nematode (Figure 6).

\section{Enzyme Activity of rTsGS}

As shown in Figure 7A, the rTsGS enzyme activity increased with an elevation of rTsGS concentration and tended to be stable when the rTsGS concentration was $0.95 \mu \mathrm{g} / \mu \mathrm{l}$. The optimal $\mathrm{pH}$ value for rTsGS activity is 7.0, and the optimal temperature is $45^{\circ} \mathrm{C}$ (Figures $7 \mathbf{B}, \mathbf{C}$ ). $\mathrm{Mg}^{2+}$ is necessary for the $\mathrm{rTs} G S$ enzymatic activity (Figure 7D). Both EDTA and glufosinate could inhibit the rTsGS enzyme activity (Figure 7E). The hydrolytic roles of rTsGS on three substrates (Glu, ATP, and $\mathrm{NH}_{4}{ }^{+}$) obeyed simple Michaelise-Menten kinetics, and the kinetic parameters of different zymolytes were $V_{\max } 0.05 \mu \mathrm{M} \mathrm{min}{ }^{-1}$ and $\mathrm{Km} 0.20 \mathrm{mM}$

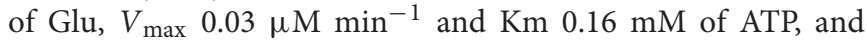
$V_{\max } 0.03 \mu \mathrm{M} \mathrm{min}{ }^{-1}$ and $\mathrm{Km} 0.17 \mathrm{mM}$ of $\mathrm{NH}_{4}{ }^{+}$, respectively (Figures 7F,G).

The enzymatic activity of natural TsGS in crude proteins of various worm stages was also determined. The results showed that the TsGS activity in 6- and 10-h IIL was significantly higher than in other worm stages (ML, AW, and NBL) $(F=33.665$, $P<0.01$ ) (Figure $7 \mathbf{H}$ ).

\section{Delivery of siRNA Into Trichinella spiralis Muscle Larvae}

At $12 \mathrm{~h}$ after electroporation with control siRNA-labeled FAM, green fluorescence staining was observed in the ML gut under fluorescence microscopy, but no fluorescence staining was found in the untreated ML (Figure 8), indicating that siRNA was successfully introduced into the ML by the electroporation technique. After the transfected ML were cultivated for 3 days, the larval mortality of siRNA-356, control siRNA, the inhibitor glufosinate, and the PBS group was $3.74,2.95,3.28$, and $3.14 \%$, respectively, $(F=0.487, P>0.05)$, suggesting that siRNA had no obvious effect on larval survival.

\section{Reduction of TsGS Expression and Activity After Silencing the TsGS Gene}

Compared with control siRNA and the PBS group, TsGS mRNA and the protein expression level in ML treated with $3 \mu \mathrm{M}$ siRNA356 were reduced by 58.48 and $71.89 \%$, respectively $(P<0.01)$ (Figures 9A,B). After being treated with $3 \mu \mathrm{M}$ siRNA-356 for 3 days, TsGS mRNA and the protein expression level were decreased by 66.67 and 54.49\% $(P<0.05)$ (Figures 9C,D).
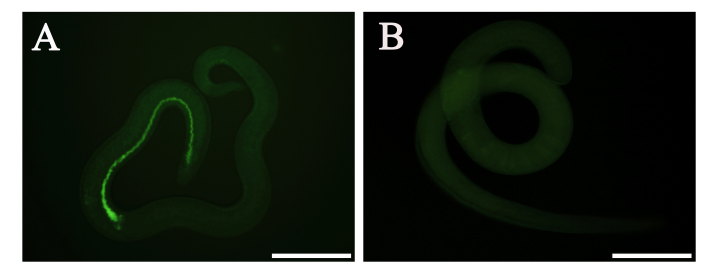

FIGURE 8 | Introduction of control siRNA by electroporation. (A) Introduction of FAM-labeled siRNA into the muscle larvae at $12 \mathrm{~h}$ after electroporation. (B) No green fluorescence was observed in the untreated larvae. Scale bars $=100 \mu \mathrm{m}$.

However, the TsGS expression levels were not reduced when the ML were treated using control siRNA. Additionally, when a T. spiralis aspartyl aminopeptidase gene (TsAAP, GenBank: KRY29491.1) was used as a control, the TsAAP expression was not suppressed in ML treated with TsGS-specific siRNA-356 (Figure 9E), suggesting that siRNA-356 is TsGS specific. The results of the enzymatic activity assay showed that the natural TsGS enzyme activity in the somatic soluble proteins of siRNAtransfected ML was decreased by $37.42 \%$ compared with the non-treated ML $(P<0.05)$ (Figure 9F).

\section{Effects of Acidic Conditions on Larval Survival and TsGS Activity}

The results of the $\mathrm{ML}$ acid resistance assay showed that the larval survival of the ML cultured at $\mathrm{pH} 2.5$ for 2.5, 12, and $18 \mathrm{~h}$ was evidently lower than the ML cultured at $\mathrm{pH} 7.4$ $\left(\chi^{2} 2.5 h=10.526, P<0.05 ; \chi^{2}{ }_{12} h=19.207, \chi^{2}{ }_{18} h=25.464\right.$, $P<0.0001$ ) (Figure 10A). After culturing for $18 \mathrm{~h}$, the enzymatic activity of native TsGS in crude proteins of the ML at $\mathrm{pH} 2.5$ was statistically lower than that at $\mathrm{pH} 4.5$ and $7.4(F=22.222$, $P<0.05$ ) (Figure 10B). When the ML was cultured at $\mathrm{pH} 2.5$ for 48 and $72 \mathrm{~h}$, a supplement of glutamine in the medium obviously increased the larval survival; the larval survival rate was elevated with the increase of glutamine doses $\left(r_{48} h=0.891\right.$, $r_{72 h}=0.969, P<0.05$ ) (Figure 10C), suggesting that the ML acid resistance was dependent on glutamine dose under in vitro culture condition.

To evaluate the effects of silencing the TsGS gene on the ML acid resistance, the survival of the siRNA-356-treated ML was also observed. The result revealed that, after being cultured at $\mathrm{pH} 2.5$ for 24 and $48 \mathrm{~h}$, the survival of siRNA-356-treated ML declined by 35.32 and $71.97 \%$ compared to the PBS group $\left(\chi^{2}{ }_{24 h}=15.726, \chi^{2} 48 h=22.134, P<0.0001\right)$ (Figures 10D-F). When siRNA-356-treated ML were cultured at $\mathrm{pH} 2.5$ for 12, 24, and $48 \mathrm{~h}$, larval survival was declined by $31.48,49.45$, and $88.41 \%$ compared to the pH 7.4 group $\left(\chi^{2} 12 h=36.686, \chi^{2}{ }_{24} h=63.139\right.$, $\left.\chi^{2} 48 h=152.616, P<0.0001\right)$, suggesting that TsGS is involved in $\mathrm{ML}$ acid resistance.

\section{siRNA-365 Impeded Larval Infectivity, Molting, Development, and Fecundity}

At $24 \mathrm{~h}$ after a challenge infection, the number of 24-h IIL recovered from infected mouse intestine in the siRNA-356 


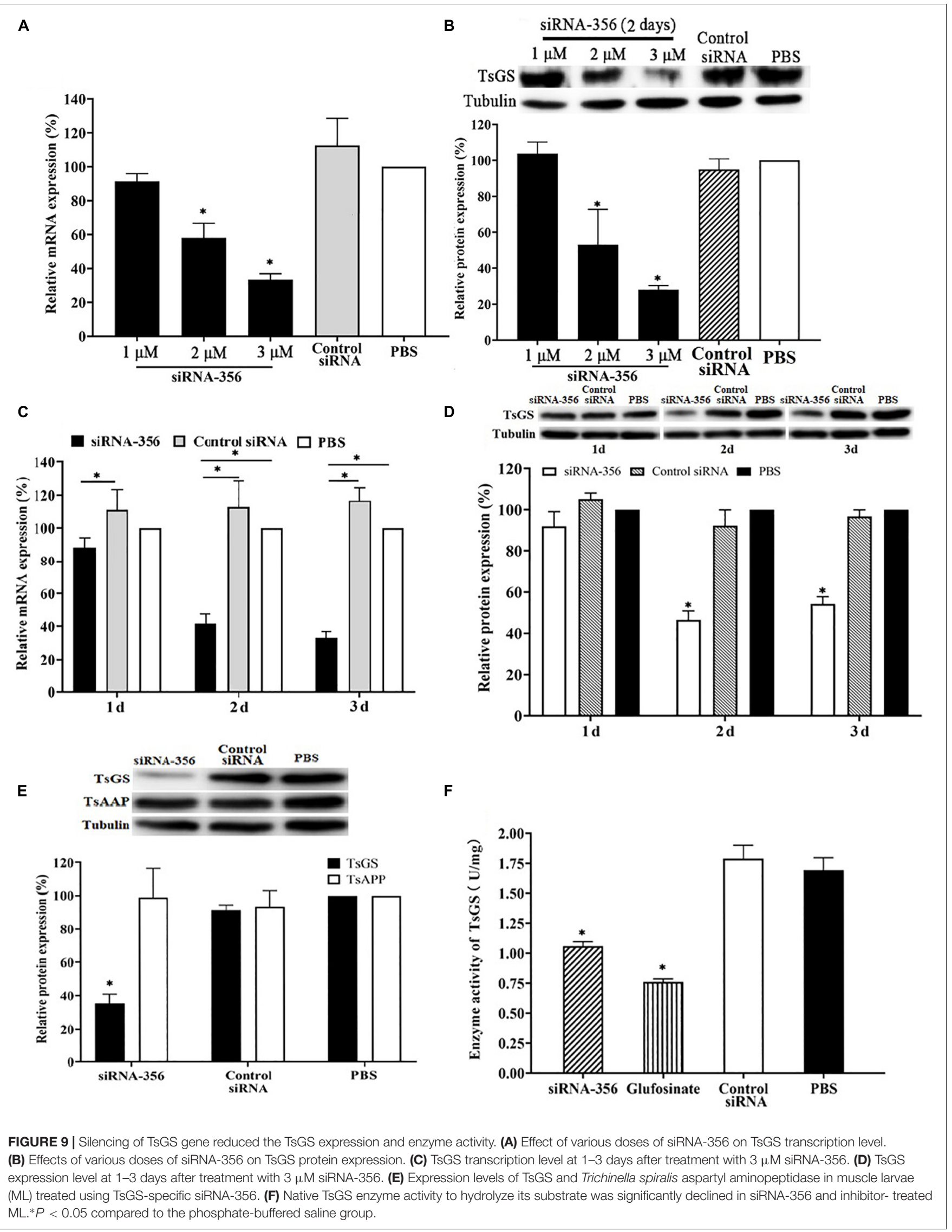


A

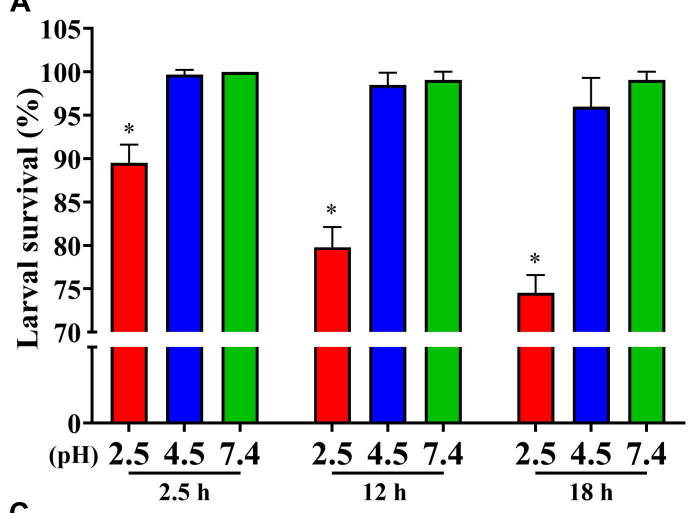

C

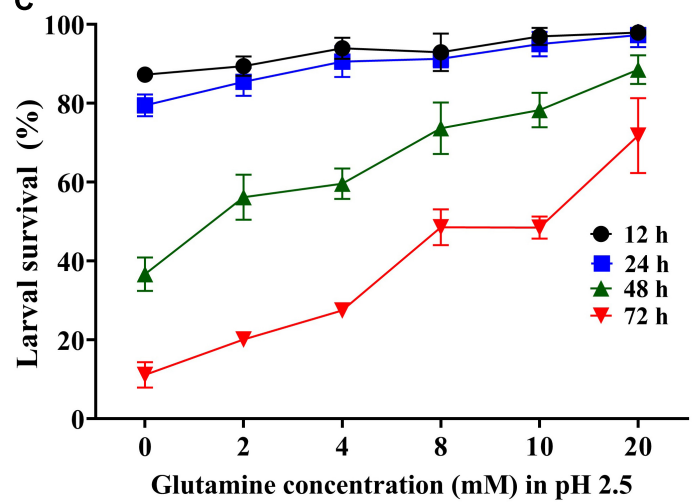

E

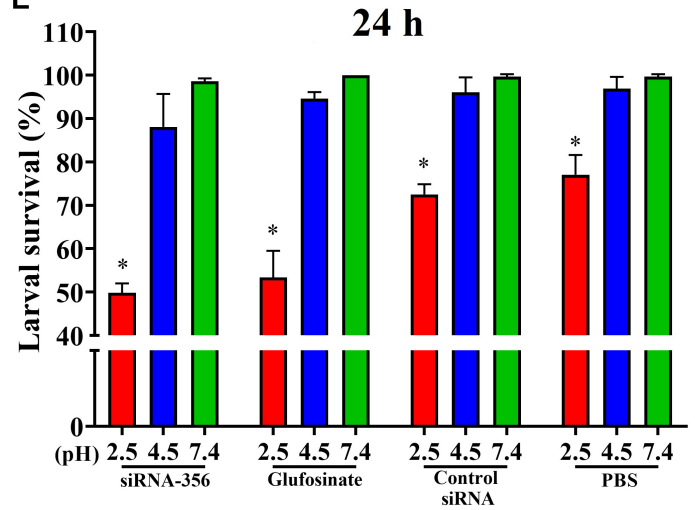

B
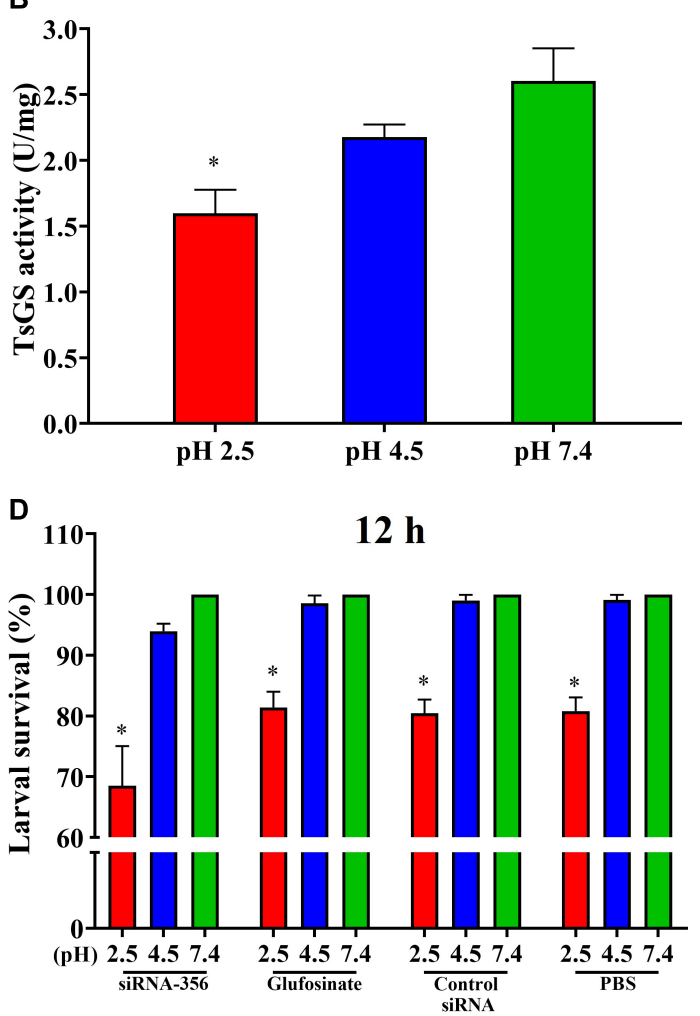

F

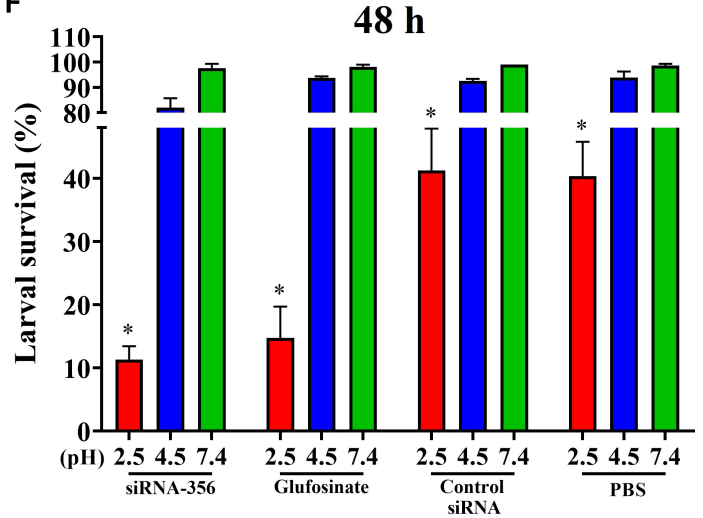

FIGURE 10 | Acid-resistant tests of Trichinella spiralis muscle larvae. The effect of various acidic conditions on the survival of $T$. spiralis muscle larvae (ML) was assessed. One hundred $\mathrm{ML}$ were cultured at $\mathrm{pH} 2.5,4.5$, and 7.4 at $37^{\circ} \mathrm{C}$ and $5 \% \mathrm{CO}_{2}$ for $2.5,12$, and $18 \mathrm{~h}$. The survival of the $\mathrm{ML}$ cultured in phosphate-buffered saline with various $\mathrm{pH}$ values was examined under a microscope on the basis of larval viability. Inactive, straight, or " $\mathrm{C}$ "-shaped larvae were assessed as dead larvae. The mobile and wriggly larvae were counted as live larvae. (A) Effect of different $\mathrm{pH}$ on $\mathrm{ML}$ survival in various culture times. (B) TsGS enzyme activity of the ML cultured at pH 2.5 for $18 \mathrm{~h}$. (C) Effect of different glutamine concentrations on the survival of ML at pH 2.5. (D-F) Silencing of TsGS gene was reduced on larval survival at $\mathrm{pH} 2.5$ for 12 (D), 24 (E), and $48 \mathrm{~h}$ (F). ${ }^{*} P<0.05$ compared to the $\mathrm{pH} 7.4$ group.

treatment group were reduced by $26.98 \%$ compared to the control siRNA and PBS group $(F=67.220, P<0.0001)$ (Figure 11A). The molting percentage of siRNA-365, control siRNA, inhibitor, and PBS group were 26.61, 46.41, 28.22, and 50.43\%, respectively $(F=39.452, P<0.0001)$ (Figure 11B). Larval molting of the siRNA-365 group was suppressed by $47.24 \%$ compared to the PBS group $(F=27.017, P<0.0001)$ (Figures 11C, 12).

The mice challenged with siRNA-356-transfected ML showed $45.70 \%$ reduction of enteral AW at 6 dpi compared with the PBS group $(F=358.483, P<0.001)$ (Figure 13A). The length of female adults of the siRNA-356 group was reduced by $25.58 \%$ relative to the control siRNA and PBS groups $(F=27.061$, $P<0.001$ ) (Figure 13B), but the male length was not obviously changed among the four groups $(P>0.05)$. The female reproduction (NBL production by each adult female) from the siRNA-365 group was prominently inferior to those of the control siRNA and PBS group ( $F=27.645, P<0.0001)$ (Figure 13C). Additionally, glutamine synthetase-specific inhibitor glufosinate 

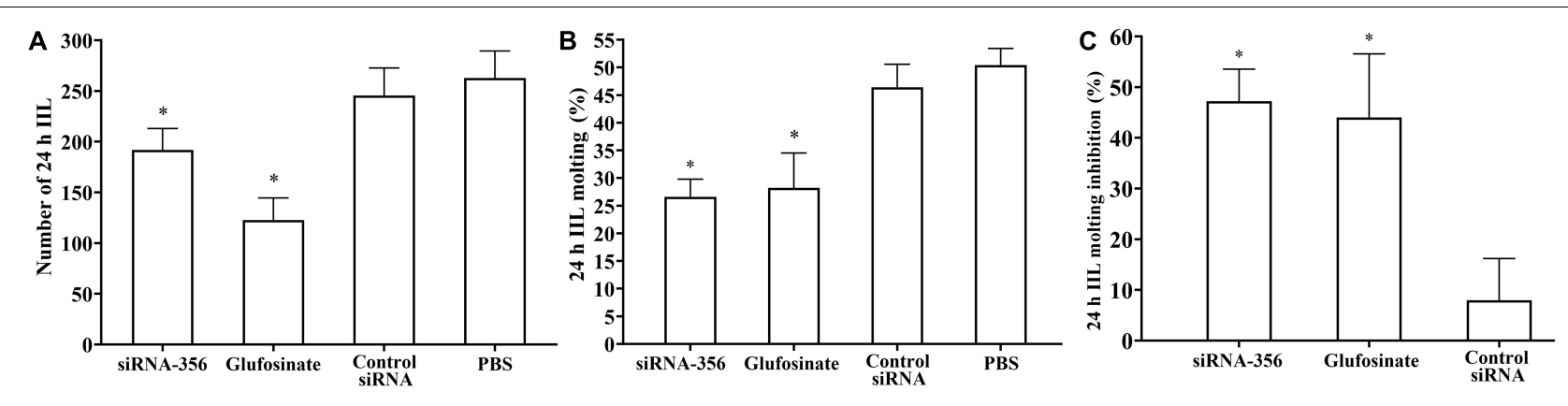

FIGURE 11 I Suppression of siRNA-356 on larval infectivity and molting. (A) Intestinal worm burden of the intestinal infectious larvae (IIL) recovered at $24 \mathrm{~h}$ post-infection $(n=10)$. (B) Molting rate of $24-h$ IIL $(n=50)$. (C) siRNA-356 inhibited IIL molting. ${ }^{*} P<0.05$ compared to the control siRNA and phosphate-buffered saline group.

also significantly mitigated the enteral worm burdens of IIL and AW, impaired larval molting, and reduced female fecundity. The results demonstrated that silencing of the TsGS gene or inhibition of TsGS activity significantly impaired larval molting, development, and female reproduction.

\section{DISCUSSION}

Glutamine synthetase participates in many biological processes and plays an extremely important role in parasites, which show metabolic characteristics to help parasites adapt to different environments in their life cycle and make use of host resources. The multiple antigens containing Leishmania chagasi GS may be optimal for protective vaccines (Martins et al., 2006). In Leishmania mexicana parasites, inhibition of the mitochondrial tricarboxylic acid circulation or GS strongly inhibited the growth and development of amastigotes in vitro (Saunders et al., 2014). In T. cruzi, GS is obligatory to resist ammonium accumulation toxicity and immune escape during host cell invasion (Crispim et al., 2018).

In the present study, TsGS has a GS catalytic domain (Glnsynt_C). The complete TsGS cDNA sequence was cloned into a pET-28a expression vector, and rTsGS was expressed in an E. coli expression system. Sequence analysis showed that TsGS had 9299\% identity with the GS of other species/gene types from the genus Trichinella, suggested that the sequences of GS are highly conserved in the genus Trichinella. Following being induced and purified, rTsGS was used to subcutaneously immunize mice and to produce anti-rTsGS serum. The anti-rTsGS IgG titer was $10^{4}$ at 2 weeks after the final immunization, suggesting that rTsGS has good immunogenicity. On Western blot analysis, rTsGS was recognized by anti-rTsGS serum, but not by infection serum and normal serum. Moreover, as shown in Figure 3B, the natural TsGS in 6-h IIL soluble and ES proteins was identified by antirTsGS serum, suggesting that TsGS was a worm somatic and ES protein. Additionally, rTsGS was not recognized by infection serum on Western blotting; it is likely because the TsGS is a moltrelated protein which is highly expressed only at the epicuticle of IIL during molting and not at epicuticle of ML and AW stages. The TsGS expressed by IIL in a short time could not stimulate the host to generate a high level of anti-TsGS antibodies during natural T. spiralis infection (Li et al., 2015).

The results of qPCR and Western blotting revealed that TsGS was transcribed and expressed in various T. spiralis stages (ML, 6- and 10-h IIL, 3-day-old AWs, and NBL), and the expression levels of TsGS mRNA and protein at 6- and 10-h IIL stages were evidently higher than those of other worm stages. After being ingested, the ML are activated into the intestinal first-stage infectious larvae (IIL1) in gut at $0.9 \mathrm{hpi}$. The IIL1 intrude the intestinal epithelium of the host and undergo the first molting to develop IIL2 prior to $10 \mathrm{hpi}$, then IIL2 molt three times to adulthood at 10-14, 15-22, and 23-30 hpi, respectively (Liu et al., 2013). In order to observe the expression of natural TsGS at various IIL stages, the 6-, 10-, 12-, 15-, 18-, 27-, and 31$\mathrm{h}$ IIL were used in the IIFA test. The results of IIFA with intact parasites showed that native TsGS was identified on the surface of IIL and NBL, but not on that of ML and AW stages. By using IIFA with parasite cross-sections, native TsGS was mainly localized at the cuticle and intrauterine embryos of the parasite. The results suggested that TsGS was closely related to the molting, growth, and development of the IIL (Ren et al., 2019). In addition, native TsGS with $41.1-67 \mathrm{kDa}$ in IIL crude proteins and ES proteins was recognized by anti-rTsGS serum; it is likely because TsGS has various isoforms. The TsGS protein might be processed by post-translational processing and modification, or it is due to the native TsGS probed by polyclonal anti-rTsGS serum (Bien et al., 2015; Cui et al., 2015b; Sun et al., 2018; Hu et al., 2020).

The enzymatic activity test showed that rTsGS had the enzymatic activity of native GS to hydrolyze its specific substrate (Glu, ATP, and $\mathrm{NH}_{4}{ }^{+}$). The optimal temperature and $\mathrm{pH}$ value of rTsGS in vitro were $45^{\circ} \mathrm{C}$ and $\mathrm{pH} 7.0$, which is similar with that of Schistosoma japonicum GS (Qiu et al., 2012). Acid resistance is the response of Trichinella ML to the $\mathrm{pH}$ change of the external environment. TsGS plays an important role in the process of glutamine synthesis within the ML worm body. Only when the ML are in acidic conditions of the host stomach do ML initiate the AR4 system to adapt to the acidic environment. The whole process of $\mathrm{ML}$ acid resistance is developed within the worm body, not in the external condition. Hence, rTsGS is inactive at acidic conditions in the external environment. The rTsGS 


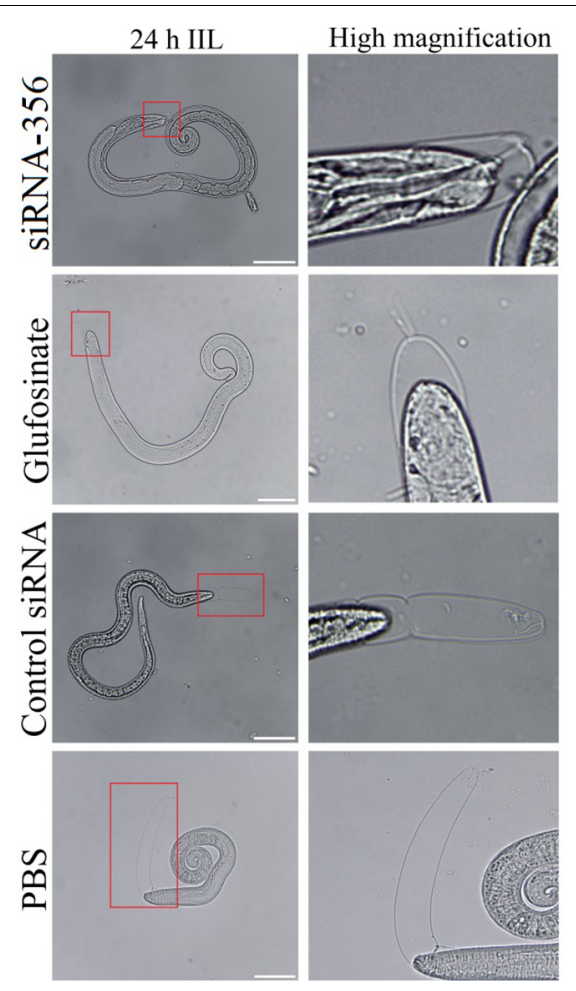

FIGURE 12 | The larval molting was suppressed by siRNA-356. In the 24-h intestinal infectious larvae (IIL) stage, the obvious suppression of larval molting was also observed in siRNA-356 and inhibitor glufosinate group. The area in the red box was magnified for observation. Scale bars $=50 \mu \mathrm{m}$.

activity was obviously enhanced by $\mathrm{Mg}^{2+}$, and $\mathrm{Mg}^{2+}$ was a TsGSdependent metal ion. Similar to other GS, rTsGS was sensitive to glufosinate and EDTA (Crispim et al., 2018). The TsGS activity in IIL stage was significantly higher than in other worm stages (as shown in Figure $\mathbf{7 H}$ ). It is likely because TsGS is involved in the molting, growth, and development of T. spiralis IIL in the host intestine. GS catalytically condenses glutamine with glutamate in the presence of ATP, $\mathrm{NH}_{4}{ }^{+}$, and $\mathrm{Mg}^{2+}$ to form glutamine, which is a carbon and nitrogen donor for the production of biomolecules and participates in redox dynamic equilibrium
(Lai et al., 2011; Wang et al., 2014). After invading into the IECs, the IIL develops into adults after molting four times. Molting is a key step for parasitic nematodes to enlarge their body size and adapt to the environment, while glutamine synthesized by GS is involved in nucleotides, amino acid synthesis, and energy metabolism in the mitochondria, which is important for larval growth and development. TsGS is involved in the synthesis of glutamine, which provides nitrogen for the production of purines, pyrimidines, amino acids, and other compounds needed for complex cellular functions.

The survival of any organisms must depend on their ability to maintain an appropriate range of $\mathrm{pH}$ values. It is known that physiological and biological buffering systems mainly rely on ammonia and carbon dioxide (Krulwich et al., 2011), which are responsible for the neutralization of acids (protons) and bases (hydroxide ions), respectively. The pathogenicity of foodborne pathogens determines the inevitability of their acid resistance. Stimulation of an acidic environment induces the expression of acid-resistant genes in pathogens, which is an important cause of disease (Djoko et al., 2017). A glutamine-dependent acidresistant system is one of the important acid-resistant systems in E. coli, and it uses amino acid antiporter GadC to absorb the intracellular YbaS of Gln and catalyze the hydrolysis of Gln to Glu and $\mathrm{NH}_{3}$, which consumes GadC and is transported out of the cell by GadC and continues to transfer into Gln. Glutamine transport and hydrolysis can help E. coli maintain acid-base balance (Kowalczyk et al., 2011; Wu et al., 2013). The acidic environment in the stomach of the host can also stimulate the effective expression of acid-fast genes of T. spiralis ML. A previous study showed that a glutaminase (TsGLS) plays an important role in the acid-resistant system of T. spiralis (Gao et al., 2021). As shown in Figures 10A,B, when the ML were cultured at $\mathrm{pH} 2.5$ for $18 \mathrm{~h}$, the larval survival was more obviously decreased at $\mathrm{pH} 2.5$ than that at $\mathrm{pH} 4.5$ and 7.4, and the enzyme activity of TsGS was significantly lower than that of the ML at $\mathrm{pH}$ 7.4. The ML survival decrease at $\mathrm{pH} 2.5$ is likely because the decreased enzyme activity of TsGS led to the reduction of glutamine synthesis, which impeded the activation of the AR4 system in ML. Therefore, partial ML were not adaptable to an acidic environment and died. Our results indicated that GS is also involved in T. spiralis ML acid resistance, and the supplement of glutamine in culture medium obviously increased the larval survival at $\mathrm{pH} 2.5$ acid
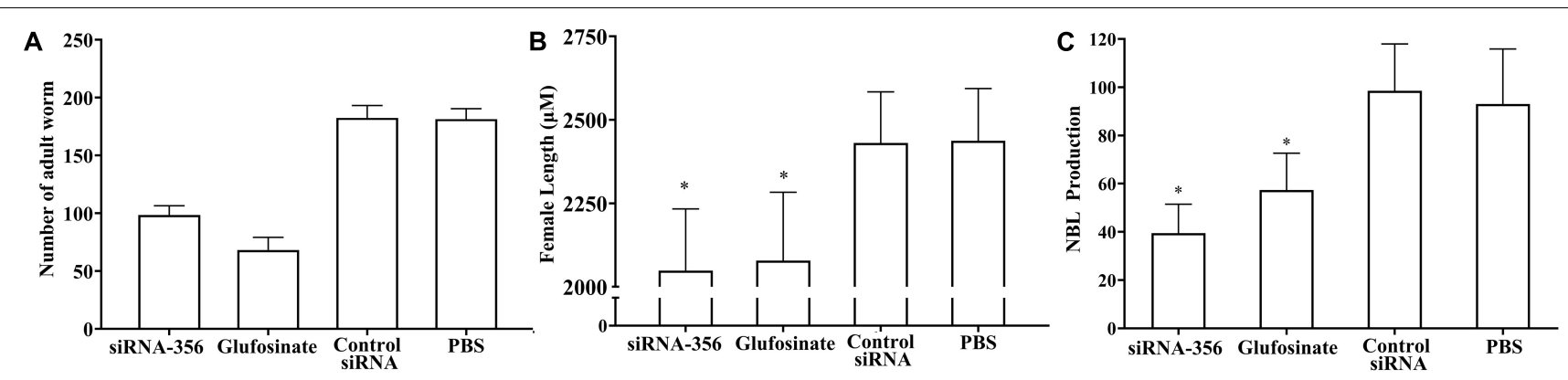

FIGURE 13 | Intestinal adult burden, female length, and fecundity of mice infected with muscle larvae transfected with siRNA-356. (A) Intestinal adult burdens $(n=10)$. (B) Female adult length $(n=30)$. (C) Female fecundity $(n=10) .{ }^{*} P<0.0001$ compared with the control siRNA and phosphate-buffered saline group. 
environments. Glutamine is a key amino acid in biosynthesis, and it has the basic functions of providing amino acids, lipids, nucleotides, hexosamine, and polyamines, but it also provides metabolic energy (ATP) as a multi-functional cellular signal molecule (Mates et al., 2019). In addition, glutamine is an indispensable substance for the production of glutathione, and glutathione is the most important antioxidant molecule and anabolism adaptation enzyme in cells. Moreover, silencing of the TsGS gene significantly reduced the survival of the ML at $\mathrm{pH}$ 2.5 compared to the normal ML at $\mathrm{pH} 2.5$ and the siRNA-356treated $\mathrm{ML}$ at $\mathrm{pH}$ 7.4. The results further indicated that TsGS participates in T. spiralis larval acid resistance, and glutamine is also an essential component of this AR.

As an important means of studying gene function, RNA interference technology is widely used to identify genes related to the growth and development of parasites, such as Fasciola hepatica, S. japonicum, and Ascaris suis (Chen et al., 2011). In the parasitic nematode $T$. spiralis, silencing of some genes evidently suppressed larval invasion of the intestinal epithelium and impeded worm development and reproduction (Han et al., 2020; Yi et al., 2020). In this study, TsGS-specific siRNA-356 was introduced into the ML by electroporation. After the ML was treated with $3 \mu \mathrm{M}$ siRNA-356 for 3 days, the TsGS expression and activity were decreased by 66.67 and $37.42 \%$, respectively. The results of the challenge infection showed that silencing of the TsGS gene significantly reduced the intestinal 24-h IIL burden and impaired the IIL molting. Intestinal adult burden, worm development, and female fecundity were also obviously impeded by TsGS-specific siRNA as demonstrated by shorter female adults and lower female reproduction capacity. The results demonstrated that TsGS plays an essential role for larval molting, development, and female reproduction in the life cycle of T. spiralis (Yang et al., 2019).

In conclusion, TsGS was highly expressed at the molting IIL stage in the $T$. spiralis life cycle and principally located at the cuticle and around embryos in the uterus of the parasite. The rTsGS had good immunogenicity and the enzymatic activity of natural GS to hydrolyze the substrate (Glu, ATP, and $\mathrm{NH}_{4}{ }^{+}$). Silencing of the TsGS gene significantly decreased the IIL survival at acidic condition, reduced intestinal 24-h IIL burden, and impaired the IIL molting, development, and female fecundity. The results indicated that TsGS is involved

\section{REFERENCES}

Bien, J., Cabaj, W., and Moskwa, B. (2015). Proteomic analysis of potential immunoreactive proteins from muscle larvae and adult worms of Trichinella spiralis in experimentally infected pigs. Folia Parasitol. 62:2015.022. doi: 10. 14411/fp.2015.022

Chen, N., Xu, M. J., Nisbet, A. J., Huang, C. Q., Lin, R. Q., Yuan, Z. G., et al. (2011). Ascaris suum: RNAi mediated silencing of enolase gene expression in infective larvae. Exp. Parasitol. 127, 142-146. doi: 10.1016/j.exppara.2010. 07.019

Crispim, M., Damasceno, F. S., Hernandez, A., Barison, M. J., Sauter, I. P., Pavani, R. S., et al. (2018). The glutamine synthetase of Trypanosoma cruzi is required for its resistance to ammonium accumulation and evasion of the parasitophorous vacuole during host-cell infection. PLoS Neglect. Trop. D 12:e006170. doi: 10.1371/journal.pntd.0006170 in ML acid resistance and the IIL molting, development, and reproduction at the intestinal stage of the $T$. spiralis life cycle, and it might be a candidate vaccine target against Trichinella molting and development.

\section{DATA AVAILABILITY STATEMENT}

The original contributions presented in the study are included in the article/Supplementary Material, further inquiries can be directed to the corresponding authors.

\section{ETHICS STATEMENT}

The animal study was reviewed and approved by the Life Science Ethics Committee of Zhengzhou University.

\section{AUTHOR CONTRIBUTIONS}

ZQW and JC designed this study. TXZ, ZW, YYS, SWY, RDL, and XZ conducted the experiments. TXZ, ZQW, and JC drafted and revised the manuscript. All authors read and approved the final version of this manuscript.

\section{FUNDING}

This study was supported by grants from the National Natural Science Foundation of China (81871673 and U1704284).

\section{ACKNOWLEDGMENTS}

We thank Hu Nan Ren for her technical help.

\section{SUPPLEMENTARY MATERIAL}

The Supplementary Material for this article can be found online at: https://www.frontiersin.org/articles/10.3389/fcell.2021. 729402/full\#supplementary-material

Cui, J., Han, Y., Yue, X., Liu, F., Song, Y. Y., Yan, S. W., et al. (2019). Vaccination of mice with a recombinant novel cathepsin B inhibits Trichinella spiralis development, reduces the fecundity and worm burden. Parasit Vectors 12:581. doi: 10.1186/s13071-019-3833-9

Cui, J., Jiang, P., Liu, L. N., and Wang, Z. Q. (2013a). Survey of Trichinella infections in domestic pigs from northern and eastern Henan. China. Vet. Parasitol. 194, 133-135. doi: 10.1016/j.vetpar.2013. 01.038

Cui, J., Ren, H. J., Liu, R. D., Wang, L., Zhang, Z. F., and Wang, Z. Q. (2013b). Phage-displayed specific polypeptide antigens induce significant protective immunity against Trichinella spiralis infection in BALB/c mice. Vaccine 31, 1171-1177. doi: 10.1016/j.vaccine.2012.12.070

Cui, J., Li, L. G., Jiang, P., Liu, R. D., Yang, X., Liu, L. N., et al. (2015a). Biochemical and functional characterization of the glutathione S-transferase from Trichinella spiralis. Parasitol. Res. 114, 2007-2013. 
Cui, J., Wang, L., Sun, G. G., Liu, L. N., Zhang, S. B., Liu, R. D., et al. (2015b). Characterization of a Trichinella spiralis $31 \mathrm{kDa}$ protein and its potential application for the serodiagnosis of trichinellosis. Acta Trop. 142, 57-63. doi: 10.1016/j.actatropica.2014.10.017

Djoko, K. Y., Phan, M. D., Peters, K. M., Walker, M. J., Schembri, M. A., and McEwan, A. G. (2017). Interplay between tolerance mechanisms to copper and acid stress in Escherichia coli. Proc. Natl. Acad. Sci. U.S.A. 114, 6818-6823. doi: 10.1073/pnas.1620232114

Gagliardo, L. F., McVay, C. S., and Appleton, J. A. (2002). Molting, ecdysis, and reproduction of Trichinella spiralis are supported in vitro by intestinal epithelial cells. Infect. Immun. 70, 1853-1859. doi: 10.1128/iai.70.4.1853-1859. 2002

Gao, Y., Meng, X., Yang, X., Meng, S., Han, C., Li, X., et al. (2021). RNAi-mediated silencing of Trichinella spiralis glutaminase results in reduced muscle larval infectivity. Vet. Res. 52:51. doi: 10.1186/s13567-021-00921-1

Guo, K. X., Bai, Y., Ren, H. N., Sun, X. Y., Song, Y. Y., Liu, R. D., et al. (2020). Characterization of a Trichinella spiralis aminopeptidase and its participation in invasion, development and fecundity. Vet. Res. 51:78. doi: 10.1186/s13567020-00805-W

Han, Y., Yue, X., Hu, C. X., Liu, F., Liu, R. D., He, M. M., et al. (2020). Interaction of a Trichinella spiralis cathepsin B with enterocytes promotes the larval intrusion into the cells. Res. Vet. Sci. 130, 110-117. doi: 10.1016/j.rvsc.2020.03.012

Hu, C. X., Jiang, P., Yue, X., Zeng, J., Zhang, X. Z., Song, Y. Y., et al. (2020). Molecular characterization of a Trichinella spiralis elastase-1 and its potential as a diagnostic antigen for trichinellosis. Parasit Vectors 13:97. doi: 10.1186/ s13071-020-3981-y

Hu, C. X., Zeng, J., Hao, H. N., Xu, Y. X. Y., Liu, F., Liu, R. D., et al. (2021). Biological properties and roles of a Trichinella spiralis inorganic pyrophosphatase in molting and developmental process of intestinal larval stages. Vet. Res. 52:6. doi: 10.1186/s13567-020-00877-8

Jiang, P., Wang, Z. Q., Cui, J., and Zhang, X. (2012). Comparison of artificial digestion and Baermann's methods for detection of Trichinella spiralis preencapsulated larvae in muscles with low-level infections. Foodborne Pathog. Dis. 9, 27-31. doi: 10.1089/fpd.2011.0985

Jiang, P., Zhang, X., Wang, L. A., Han, L. H., Yang, M., Duan, J. Y., et al. (2016). Survey of Trichinella infection from domestic pigs in the historical endemic areas of Henan province, central China. Parasitol. Res. 115, 4707-4709. doi: 10.1007/s00436-016-5240-x

Jin, Y., Watt, R. M., Danchin, A., and Huang, J. D. (2009). Small noncoding RNA $\mathrm{GcvB}$ is a novel regulator of acid resistance in Escherichia coli. BMC Genomics 10:165. doi: 10.1186/1471-2164-10-165

Kowalczyk, L., Ratera, M., Paladino, A., Bartoccioni, P., Errasti-Murugarren, E., Valencia, E., et al. (2011). Molecular basis of substrate-induced permeation by an amino acid antiporter. Proc. Natl. Acad. Sci .U.S.A. 108, 3935-3940. doi: $10.1073 /$ pnas. 1018081108

Krulwich, T. A., Sachs, G., and Padan, E. (2011). Molecular aspects of bacterial pH sensing and homeostasis. Nat. Rev. Microbiol. 9, 330-343. doi: 10.1038/ nrmicro2549

Kumada, Y., Benson, D. R., Hillemann, D., Hosted, T. J., Rochefort, D. A., Thompson, C. J., et al. (1993). Evolution of the glutamine synthetase gene, one of the oldest existing and functioning genes. Proc. Natl. Acad. Sci. U.S.A. 90, 3009-3013. doi: 10.1073/pnas.90.7.3009

Lai, X. F., Gao, H., Kong, J., Wang, Q. Y., Wang, W. J., and Meng, X. H. (2011). Cloning and characterization of the glutamine synthetase gene from Chinese shrimp Fenneropenaeus chinensis. Aquacult. Int. 19, 873-889.

Lei, J. J., Hu, Y. Y., Liu, F., Yan, S. W., Liu, R. D., Long, S. R., et al. (2020). Molecular cloning and characterization of a novel peptidase from Trichinella spiralis and protective immunity elicited by the peptidase in BALB/c mice. Vet. Res. 51:111. doi: 10.1186/s13567-020-00838-1

Li, L. G., Wang, Z. Q., Liu, R. D., Yang, X., Liu, L. N., Sun, G. G., et al. (2015). Trichinella spiralis: low vaccine potential of glutathione S-transferase against infections in mice. Acta Trop. 146, 25-32. doi: 10.1016/j.actatropica.2015. 02.020

Li, Y., Yang, G., Huang, X., Ye, B., Liu, M., Lin, Z., et al. (2009). Recombinant glutamine synthetase (GS) from C. glutamicum existed as both hexamers \& dedocamers and C-terminal His-tag enhanced inclusion bodies formation in E. coli. Appl. Biochem. Biotechnol. 159, 614-622. doi: 10.1007/s12010-0088493-8
Liu, C. Y., Ren, H. N., Song, Y. Y., Sun, G. G., Liu, R. D., Jiang, P., et al. (2018). Characterization of a putative glutathione S-transferase of the parasitic nematode Trichinella spiralis. Exp. Parasitol. 187, 59-66. doi: 10.1016/j.exppara. 2018.02.005

Liu, C. Y., Song, Y. Y., Ren, H. N., Sun, G. G., Liu, R. D., Jiang, P., et al. (2017). Cloning and expression of a Trichinella spiralis putative glutathione S-transferase and its elicited protective immunity against challenge infections. Parasit Vectors 10:448. doi: 10.1186/s13071-017-2384-1

Liu, L. N., Wang, Z. Q., Zhang, X., Jiang, P., Qi, X., Liu, R. D., et al. (2015). Characterization of Spirometra erinaceieuropaei plerocercoid cysteine protease and potential application for serodiagnosis of sparganosis. PLoS Negl. Trop. Dis. 9:e0003807. doi: 10.1371/journal.pntd.0003807

Liu, P., Cui, J., Liu, R. D., Wang, M., Jiang, P., Liu, L. N., et al. (2015). Protective immunity against Trichinella spiralis infection induced by TsNd vaccine in mice. Parasit Vectors 8:185. doi: 10.1186/s13071-015-0791-8

Liu, R. D., Wang, Z. Q., Wang, L., Long, S. R., Ren, H. J., and Cui, J. (2013). Analysis of differentially expressed genes of Trichinella spiralis larvae activated by bile and cultured with intestinal epithelial cells using real-time PCR. Parasitol. Res. 112, 4113-4120. doi: 10.1007/s00436-013-3602-1

Long, S. R., Wang, Z. Q., Jiang, P., Liu, R. D., Qi, X., Liu, P., et al. (2015). Characterization and functional analysis of Trichinella spiralis Nudix hydrolase. Exp. Parasitol. 159, 264-273. doi: 10.1016/j.exppara.2015.10.009

Long, S. R., Wang, Z. Q., Liu, R. D., Liu, L. N., Li, L. G., Jiang, P., et al. (2014). Molecular identification of Trichinella spiralis nudix hydrolase and its induced protective immunity against trichinellosis in BALB/c mice. Parasit Vectors 7:600. doi: 10.1186/s13071-014-0600-9

Martins, D. R. A., Jeronimo, S. M. B., Donelson, J. E., and Wilson, M. E. (2006). Leishmania chagasi $\mathrm{T}$-cell antigens identified through a double library screen. Infect. Immun. 74, 6940-6948. doi: 10.1128/IAI.02032-05

Mates, J. M., Campos-Sandoval, J. A., Santos-Jimenez, J. L., and Marquez, J. (2019). Dysregulation of glutaminase and glutamine synthetase in cancer. Cancer Lett. 467, 29-39. doi: 10.1016/j.canlet.2019.09.011

Qi, X., Han, Y., Jiang, P., Yue, X., Ren, H. N., Sun, G. G., et al. (2018a). Oral vaccination with Trichinella spiralis DNase II DNA vaccine delivered by attenuated Salmonella induces a protective immunity in BALB/c mice. Vet. Res. 49:119. doi: 10.1186/s13567-018-0614-y

Qi, X., Yue, X., Han, Y., Jiang, P., Yang, F., Lei, J. J., et al. (2018b). Characterization of Two Trichinella spiralis adult-specific DNase II and their capacity to induce protective immunity. Front. Microbiol. 9:2504. doi: 10.3389/fmicb.2018.02504

Qiu, C., Hong, Y., Cao, Y., Wang, F., Fu, Z., Shi, Y., et al. (2012). Molecular cloning and characterization of glutamine synthetase, a tegumental protein from Schistosoma japonicum. Parasitol. Res. 111, 2367-2376.

Ren, H. J., Cui, J., Wang, Z. Q., and Liu, R. D. (2011). Normal mouse intestinal epithelial cells as a model for the in vitro invasion of Trichinella spiralis infective larvae. PLoS One 6:e0027010. doi: 10.1371/journal.pone.002 7010

Ren, H. J., Cui, J., Yang, W., Liu, R. D., and Wang, Z. Q. (2013). Identification of differentially expressed genes of Trichinella spiralis larvae after exposure to host intestine milieu. PLoS One 8:e0067570. doi: 10.1371/journal.pone.0067570

Ren, H. N., Guo, K. X., Zhang, Y., Sun, G. G., Liu, R. D., Jiang, P., et al. (2018). Molecular characterization of a $31 \mathrm{kDa}$ protein from Trichinella spiralis and its induced immune protection in BALB/c mice. Parasit Vectors 11:625. doi: 10.1186/s13071-018-3198-5

Ren, H. N., Liu, R. D., Song, Y. Y., Zhuo, T. X., Guo, K. X., Zhang, Y., et al. (2019). Label-free quantitative proteomic analysis of molting-related proteins of Trichinella spiralis intestinal infective larvae. Vet. Res. 50:70. doi: 10.1186/ s13567-019-0689-0

Rostami, A., Gamble, H. R., Dupouy-Camet, J., Khazan, H., and Bruschi, F. (2017). Meat sources of infection for outbreaks of human trichinellosis. Food Microbiol. 64, 65-71. doi: 10.1016/j.fm.2016.12.012

Saunders, E. C., Ng, W. W., Kloehn, J., Chambers, J. M., Ng, M., and McConville, M. J. (2014). Induction of a stringent metabolic response in intracellular stages of Leishmania mexicana leads to increased dependence on mitochondrial metabolism. PLoS Pathog. 10:e1003888. doi: 10.1371/journal.ppat.1003888

Sun, G. G., Lei, J. J., Ren, H. N., Zhang, Y., Guo, K. X., Long, S. R., et al. (2019). Intranasal immunization with recombinant Trichinella spiralis serine protease elicits protective immunity in BALB/c mice. Exp. Parasitol. 201, 1-10. doi: 10.1016/j.exppara.2019.04.006 
Sun, G. G., Liu, R. D., Wang, Z. Q., Jiang, P., Wang, L., Liu, X. L., et al. (2015a). New diagnostic antigens for early trichinellosis: the excretory-secretory antigens of Trichinella spiralis intestinal infective larvae. Parasitol. Res. 114, 4637-4644. doi: 10.1007/s00436-015-4709-3

Sun, G. G., Wang, Z. Q., Liu, C. Y., Jiang, P., Liu, R. D., Wen, H., et al. (2015b). Early serodiagnosis of trichinellosis by ELISA using excretory-secretory antigens of Trichinella spiralis adult worms. Parasit Vectors 8:484. doi: 10.1186/s13071-0151094-9

Sun, G. G., Song, Y. Y., Jiang, P., Ren, H. N., Yan, S. W., Han, Y., et al. (2018). Characterization of a Trichinella spiralis putative serine protease. Study of its potential as sero-diagnostic tool. PLoS Negl. Trop. Dis. 12:e0006485. doi: 10. 1371/journal.pntd.0006485

Wang, J., Zhou, W., Chen, H., Zhan, J., He, C., and Wang, Q. (2018). Ammonium nitrogen tolerant Chlorella strain screening and its damaging effects on photosynthesis. Front. Microbiol. 9:3250. doi: 10.3389/fmicb.2018. 03250

Wang, L., Wang, Z. Q., and Cui, J. (2013). Proteomic analysis of the changed proteins of Trichinella spiralis infective larvae after co-culture in vitro with intestinal epithelial cells. Vet. Parasitol. 194, 160-163. doi: 10.1016/j.vetpar. 2013.01.045

Wang, X. L., Li, Y. Z., Yan, Y., Xu, B. H., and Guo, X. Q. (2014). Identification and abiotic stress response of a glutamine synthetase gene (AccGS) from the Asiatic honeybee, Apis cerana cerana (Hymenoptera: Apidae). Eur. J. Entomol. 111, 1-9. doi: 10.14411/eje.2014.001

Wang, Z. Q., Li, L. Z., Jiang, P., Liu, L. N., and Cui, J. (2012). Molecular identification and phylogenetic analysis of Trichinella isolates from different provinces in mainland China. Parasitol. Res. 110, 753-757. doi: 10.1007/s00436011-2549-3

Wang, Z. Q., Zhang, S. B., Jiang, P., Liu, R. D., Long, S. R., Zhang, X., et al. (2015). The siRNA-mediated silencing of Trichinella spiralis nudix hydrolase results in reduction of larval infectivity. Parasitol. Res. 114, 3551-3557. doi: 10.1007/s00436-015-4650-5

Wu, Z., Nagano, I., and Takahashi, Y. (2013). Trichinella: what is going on during nurse cell formation? Vet. Parasitol. 194, 155-159. doi: 10.1016/j.vetpar.2013. 01.044

Wu, Z., Nagano, I., Takahashi, Y., and Maekawa, Y. (2016). Practical methods for collecting Trichinella parasites and their excretory-secretory products. Parasitol. Int. 65, 591-595. doi: 10.1016/j.parint.2016.08.001

Xu, J., Liu, R. D., Bai, S. J., Hao, H. N., Yue, W. W., Xu, Y. X. Y., et al. (2020). Molecular characterization of a Trichinella spiralis aspartic protease and its facilitation role in larval invasion of host intestinal epithelial cells. PLoS Negl. Trop. Dis. 14:e0008269. doi: 10.1371/journal.pntd.0008269

Xu, J., Yang, F., Yang, D. Q., Jiang, P., Liu, R. D., Zhang, X., et al. (2018). Molecular characterization of Trichinella spiralis galectin and its participation in larval invasion of host's intestinal epithelial cells. Vet. Res. 49:79. doi: 10.1186/s13567018-0573-3

Xu, J., Yue, W. W., Xu, Y. X. Y., Hao, H. N., Liu, R. D., Long, S. R., et al. (2021). Molecular characterization of a novel aspartyl protease-1 from Trichinella spiralis. Res. Vet. Sci. 134, 1-11. doi: 10.1016/j.rvsc.2020. 11.008
Yang, F., Guo, K. X., Yang, D. Q., Liu, R. D., Long, S. R., Zhang, X., et al. (2020). Functional analysis of Trichinella spiralis serine protease 1.2 by siRNA mediated RNA interference. Trop. Biomed. 37, 458-470.

Yang, F., Yang, D. Q., Song, Y. Y., Guo, K. X., Li, Y. L., Long, S. R., et al. (2019). In vitro silencing of a serine protease inhibitor suppresses Trichinella spiralis invasion, development, and fecundity. Parasitol. Res. 118, 2247-2255. doi: 10.1007/s00436-019-06344-4

Yang, W., Li, L. G., Liu, R. D., Sun, G. G., Liu, C. Y., Zhang, S. B., et al. (2015). Molecular identification and characterization of Trichinella spiralis proteasome subunit beta type-7. Parasit Vectors 8:18. doi: 10.1186/s13071-014-0626-z

Yang, Y., Qin, W., Tian, G., and Jian, W. (2010). Expression and functional characterization of a Rho-family small GTPase CDC42 from Trichinella spiralis. Parasitol. Res. 107, 153-162. doi: 10.1007/s00436-010-1851-9

Yi, N., Yu, P., Wu, L., Liu, Z., Guan, J., Liu, C., et al. (2020). RNAi-mediated silencing of Trichinella spiralis serpin-type serine protease inhibitors results in a reduction in larval infectivity. Vet. Res. 51:139. doi: 10.1186/s13567-02000860-3

Yue, X., Sun, X. Y., Liu, F., Hu, C. X., Bai, Y., Da Yang, Q., et al. (2020). Molecular characterization of a Trichinella spiralis serine proteinase. Vet. Res. 51:125. doi: 10.1186/s13567-020-00847-0

Zhang, S. B., Jiang, P., Wang, Z. Q., Long, S. R., Liu, R. D., Zhang, X., et al. (2016). DsRNA-mediated silencing of Nudix hydrolase in Trichinella spiralis inhibits the larval invasion and survival in mice. Exp. Parasitol. 162, 35-42. doi: 10.1016/j.exppara.2016.01.005

Zhang, X., Wang, Z. Q., Wang, S. W., Li, L. Z., Wang, M. M., Jiang, P., et al. (2010). [Effect of vinegar or soy sauce on the infectivity and reproductive capacity of Trichinella spiralis muscle larvae]. Zhongguo Ji Sheng Chong Xue Yu Ji Sheng Chong Bing Za Zhi 28, 34-37.

Zhang, X. Z., Sun, X. Y., Bai, Y., Song, Y. Y., Hu, C. X., Li, X., et al. (2020). Protective immunity in mice vaccinated with a novel elastase-1 significantly decreases Trichinella spiralis fecundity and infection. Vet. Res. 51:43. doi: 10.1186/s13567020-00767-z

Conflict of Interest: The authors declare that the research was conducted in the absence of any commercial or financial relationships that could be construed as a potential conflict of interest.

Publisher's Note: All claims expressed in this article are solely those of the authors and do not necessarily represent those of their affiliated organizations, or those of the publisher, the editors and the reviewers. Any product that may be evaluated in this article, or claim that may be made by its manufacturer, is not guaranteed or endorsed by the publisher.

Copyright (c) 2021 Zhuo, Wang, Song, Yan, Liu, Zhang, Wang and Cui. This is an open-access article distributed under the terms of the Creative Commons Attribution License (CC BY). The use, distribution or reproduction in other forums is permitted, provided the original author(s) and the copyright owner(s) are credited and that the original publication in this journal is cited, in accordance with accepted academic practice. No use, distribution or reproduction is permitted which does not comply with these terms. 